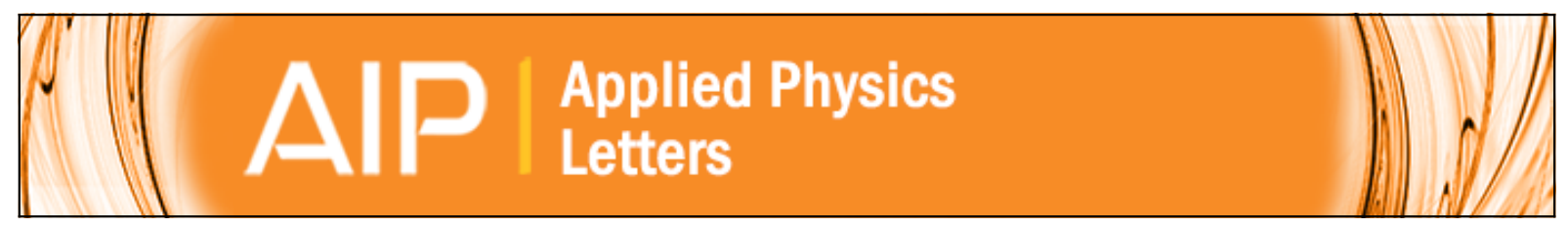

\title{
Plasma hydrogenation of strained Si / SiGe / Si heterostructure for layer transfer without ion implantation
}

Lin Shao, Yuan Lin, J. K. Lee, Q. X. Jia, Yongqiang Wang, M. Nastasi, Phillip E. Thompson, N. David Theodore, Paul K. Chu, T. L. Alford, J. W. Mayer, Peng Chen, and S. S. Lau

Citation: Applied Physics Letters 87, 091902 (2005); doi: 10.1063/1.2032602

View online: http://dx.doi.org/10.1063/1.2032602

View Table of Contents: http://scitation.aip.org/content/aip/journal/apl/87/9?ver=pdfcov

Published by the AIP Publishing

\section{Articles you may be interested in}

Controlled drive-in and precipitation of hydrogen during plasma hydrogenation of silicon using a thin compressively strained SiGe layer

Appl. Phys. Lett. 97, 031917 (2010); 10.1063/1.3467455

Effect of temperature on layer separation by plasma hydrogenation

Appl. Phys. Lett. 93, 254104 (2008); 10.1063/1.3054643

Cracking in hydrogen ion-implanted $\mathrm{Si} / \mathrm{Si} 0.8 \mathrm{Ge} 0.2 / \mathrm{Si}$ heterostructures

Appl. Phys. Lett. 92, 061904 (2008); 10.1063/1.2838338

Relaxed graded SiGe donor substrates incorporating hydrogen-gettering and buried etch stop layers for strained silicon layer transfer applications

J. Appl. Phys. 101, 013522 (2007); 10.1063/1.2405237

Plasma hydrogenation of strain-relaxed $\mathrm{Si} \mathrm{Ge} / \mathrm{Si}$ heterostructure for layer transfer

Appl. Phys. Lett. 85, 4944 (2004); 10.1063/1.1824171

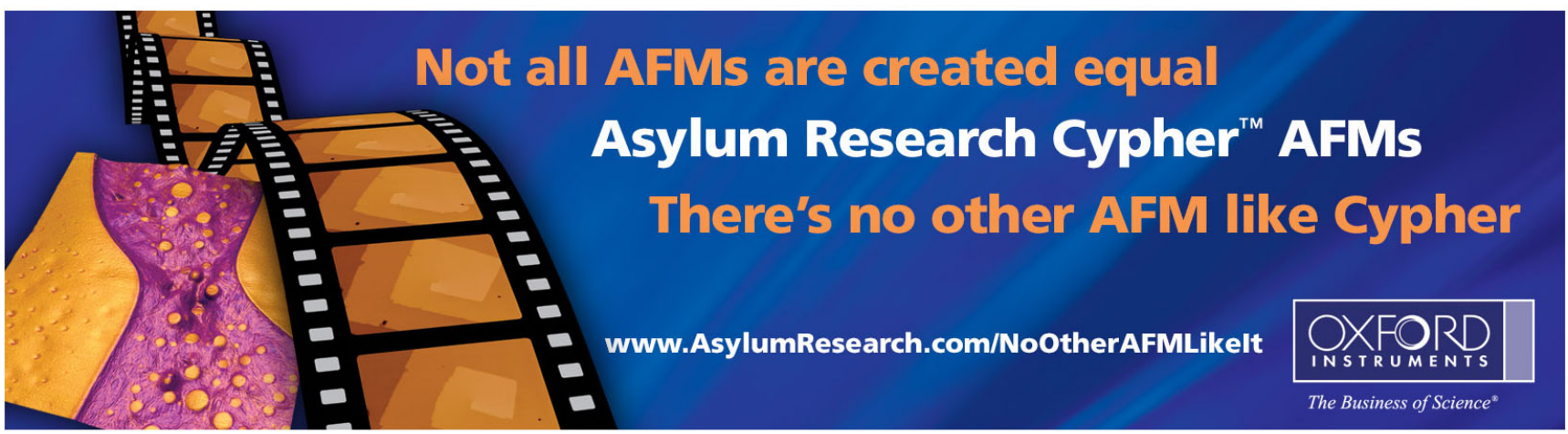




\title{
Plasma hydrogenation of strained $\mathrm{Si} / \mathrm{SiGe} / \mathrm{Si}$ heterostructure for layer transfer without ion implantation
}

\author{
Lin Shao, ${ }^{\text {a) }}$ Yuan Lin, J. K. Lee, Q. X. Jia, Yongqiang Wang, and M. Nastasi \\ Los Alamos National Laboratory, Los Alamos, New Mexico 87545 \\ Phillip E. Thompson \\ Code 6812, Naval Research Laboratory, Washington, DC 20375-5347 \\ N. David Theodore \\ Advanced Products Research and Development Laboratory, Freescale Semiconductor Inc., \\ Tempe, Arizona 85284 \\ Paul K. Chu \\ Department of Physics and Materials Science, City University of Hong Kong, Hong Kong, \\ People's Republic of China \\ T. L. Alford and J. W. Mayer \\ Department of Chemical and Materials Engineering, Arizona State University, Tempe, Arizona 85287 \\ Peng Chen and S. S. Lau \\ University of California at San Diego, San Diego, California 92093
}

(Received 15 April 2005; accepted 5 July 2005; published online 22 August 2005)

\begin{abstract}
We have developed an innovative approach without the use of ion implantation to transfer a high-quality thin Si layer for the fabrication of silicon-on-insulator wafers. The technique uses a buried strained $\mathrm{SiGe}$ layer, a few nanometers in thickness, to provide $\mathrm{H}$ trapping centers. In conjunction with $\mathrm{H}$ plasma hydrogenation, lift-off of the top Si layer can be realized with cleavage occurring at the depth of the strained SiGe layer. This technique avoids irradiation damage within the top Si layer that typically results from ion implantation used to create $\mathrm{H}$ trapping regions in the conventional ion-cut method. We explain the strain-facilitated layer transfer as being due to preferential vacancy aggregation within the strained layer and subsequent trapping of hydrogen, which lead to cracking in a well controlled manner. (c) 2005 American Institute of Physics.
\end{abstract}

[DOI: $10.1063 / 1.2032602$ ]

In the ion-cut technique for layer transfer, ${ }^{1}$ implanted hydrogen atoms (at a dose of a few $10^{16} / \mathrm{cm}^{2}$ ) create hydrogen-terminated cavities upon annealing that finally evolve into cracks parallel to the surface. Growth and joining of these cracks allows the surface layer to become completely separated from the substrate. This technique has become one of the mainstream methods used for the fabrication of silicon-on-insulator wafers. ${ }^{2,3}$ The thickness of the transferred layer in the conventional ion-cut technique (Smartcut $^{\mathrm{TM}}$ ) is controlled by adjusting the energy of the incoming $\mathrm{H}$ ions. ${ }^{1}$ For transfer of layers of less than $20 \mathrm{~nm}$ thickness, which is demanded by the international technology roadmap for the fabrication of fully depleted complementary metaloxide semiconductor devices, ${ }^{4}$ the ion-implantation-based ion-cut technique has difficulty producing effective layer transfer even if low energy hydrogen implantation is used. ${ }^{5}$ Various techniques have been developed for the transfer of ultrathin layers. ${ }^{6-11}$ Recently, it was shown that thin layer transfer can be realized by plasma hydrogenation in conjunction with a $\mathrm{H}$ trapping layer created by heavier ion implantation. ${ }^{11}$ However, heavy ion bombardment significantly degrades the Si crystalline quality.

We have developed a thin layer transfer process using a strained $\mathrm{SiGe}$ layer as a $\mathrm{H}$ trapping layer. The splitting loca-

\footnotetext{
${ }^{\text {a) }}$ Author to whom correspondence should be addressed; electronic mail:
} 1shao@mailaps.org tion is controlled by the depth of the strained SiGe layer. Therefore, the region damaged during the introduction of hydrogen is not coupled with the location of the layer splitting. This approach has a significant effect on improving the crystalline quality of the transferred thin Si layer.

Our process began by fabricating a heterostructure with a thin SiGe layer buried inside monocrystalline Si. A 5-nmthick epitaxial $\mathrm{Si}_{0.8} \mathrm{Ge}_{0.2}$ layer was grown on a (100) Si substrate and a 190-nm-thick crystalline Si layer was grown on top by molecular beam epitaxy (MBE) at $650{ }^{\circ} \mathrm{C}$. The samples were subsequently hydrogenated using a hydrogen plasma at $250-300{ }^{\circ} \mathrm{C}$ for $1 \mathrm{~h}$ and then at $300-350{ }^{\circ} \mathrm{C}$ for 2 more hours. The applied bias during hydrogenation was $-500 \mathrm{~V}$. For the purpose of comparison, a virgin $\mathrm{Si}$ wafer without a strained layer was hydrogenated simultaneously.

The strain in the sample was measured using high resolution x-ray diffraction analysis. An $\omega-2 \theta$ scan around $\mathrm{Si}(004)$ was collected using a Bede D1 x-ray diffractometer. After hydrogenation, an optical microscope with Nomarski contrast was used to check for surface bubble formation. Infrared (IR) absorption spectroscopy was used to investigate the interaction of hydrogen with defects. The hydrogen atomic profiles were measured with elastic recoil detection (ERD) analysis. ERD analysis was performed using a 3.0 $\mathrm{MeV}{ }^{4} \mathrm{He}^{+}$analyzing beam. The beam was oriented $75.25^{\circ}$ from the sample normal and the detector was positioned $150.5^{\circ}$ from the incident beam. To avoid detection of backscattered He particles, a $14-\mu \mathrm{m}$-thick Mylar foil was placed 


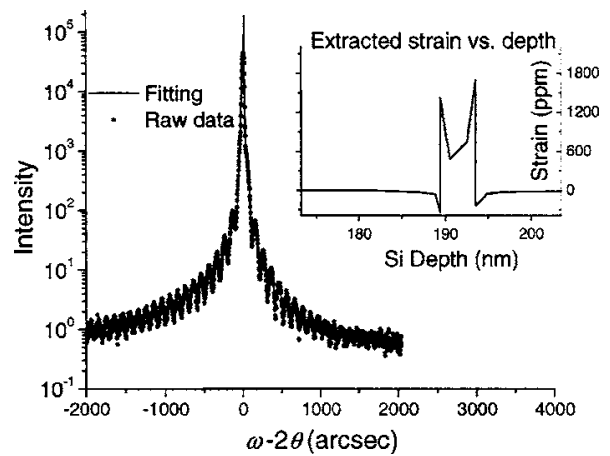

FIG. 1. X-ray $\omega-2 \theta$ scans around the $\mathrm{Si}(004)$ diffraction peak, obtained from as-grown MBE Si and the corresponding Bede RADS auto-fit to the data. The inset shows the out-of-plane strain as a function of depth.

between the sample and the hydrogen detector. Transmission electron microscopy (TEM) was used to characterize the structure of the samples.

Figure 1 shows the $\mathrm{x}$-ray diffraction intensity resulting from an $\omega-2 \theta$ scan around the $\mathrm{Si}(004)$ diffraction peak. The inset shows the strain-depth profiles of the as-grown sample from the Bede RADS auto-fit. The buried SiGe layer has a tensile out-of-plane strain peaking at $1700 \mathrm{ppm}$. The strains peak at both interfaces of the SiGe/Si. The deposited Si layer and $\mathrm{Si}$ substrate have compressive out-of-plane strains near the interfaces with the SiGe layer. The strain in the Si gradually decreases with increasing distance from the SiGe layer, disappearing for distances greater than $8 \mathrm{~nm}$. It is also noted that the thicknesses of the crystalline Si layer and the epitaxial $\mathrm{Si}_{0.8} \mathrm{Ge}_{0.2}$ extracted from x-ray diffraction are the same as the specifications of the sample fabricated by MBE.

We have observed long range $\mathrm{H}$ migration and subsequent $\mathrm{H}$ trapping by the buried strained $\mathrm{Si}_{0.8} \mathrm{Ge}_{0.2}$ layer. ERD $\mathrm{H}$ profiles after plasma hydrogenation are shown in Fig. 2. The trapped hydrogen in the MBE sample has a peak concentration of $9.6 \times 10^{20} / \mathrm{cm}^{3}$ at the depth of the strained $\mathrm{Si}_{0.8} \mathrm{Ge}_{0.2}$ layer. In the hydrogenated control sample (virgin $\mathrm{Si}$ ), $\mathrm{H}$ is only distributed narrowly in the near surface region. Since H contamination near the surface is present whether or not the sample has been hydrogenated, ERD spectra have been normalized by subtracting the nonhydrogenated spectrum.

Figure 3 shows infrared-absorption measurements from both the hydrogenated MBE sample and the control sample. The MBE sample exhibits enhanced $\mathrm{H}$ trapping by defects

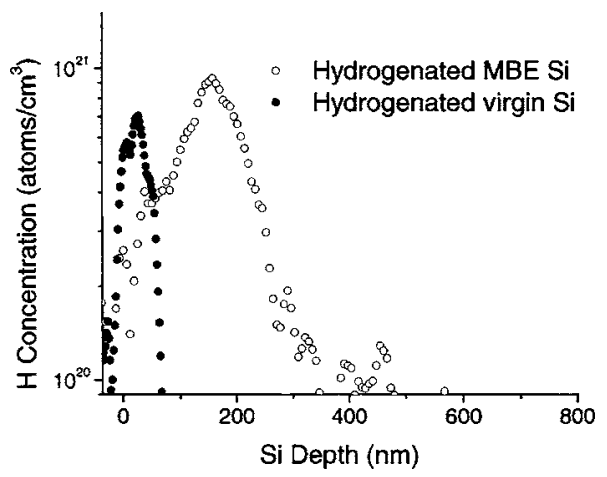

FIG. 2. Hydrogen ERD spectra from a hydrogenated MBE sample (with a strained $\mathrm{Si}_{0.8} \mathrm{Ge}_{0.2}$ layer buried at a depth of $190 \mathrm{~nm}$ ) and a hydrogenated control Si sample (without the strained laver). The ERD spectra have been normalized by subtracting the nonhydrogenated spectrum.

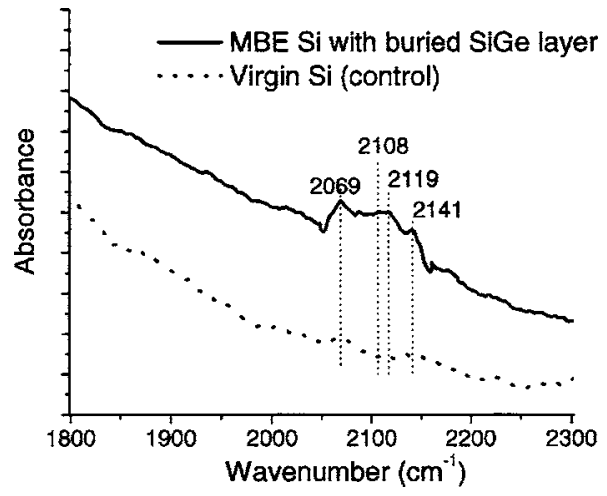

FIG. 3. Infrared absorption spectra from the hydrogenated MBE sample (with a strained layer) and the hydrogenated control Si sample (without a strained layer).

such as vacancies and internal surfaces, as evidenced by enhanced modes at 2069, 2108-2119, and $2141 \mathrm{~cm}^{-1}$. The modes at $2060-2120 \mathrm{~cm}^{-1}$ are related to hydrogen that is trapped at extended internal surfaces, and the mode at $2069 \mathrm{~cm}^{-1}$ is close to a value that has previously been assigned to a single hydrogen atom bound to a monovacancy defect. ${ }^{12}$ The small features at 2108 and $2119 \mathrm{~cm}^{-1}$ are due to symmetric and asymmetric $\mathrm{Si}-\mathrm{H}_{2}$ stretching motions on atomically rough (100) internal surfaces. ${ }^{12}$ The peak observed at $2141 \mathrm{~cm}^{-1}$ is close to the value previously assigned to a vacancy containing two hydrogen atoms within it. ${ }^{13,14}$

Microcracks are present in the MBE Si as revealed by cross-section TEM micrographs. Figure 4(a) shows that the hydrogenated control sample has a damaged layer near the surface due to the de bias applied to the substrate during hydrogenation. No microcracks were observed in the control

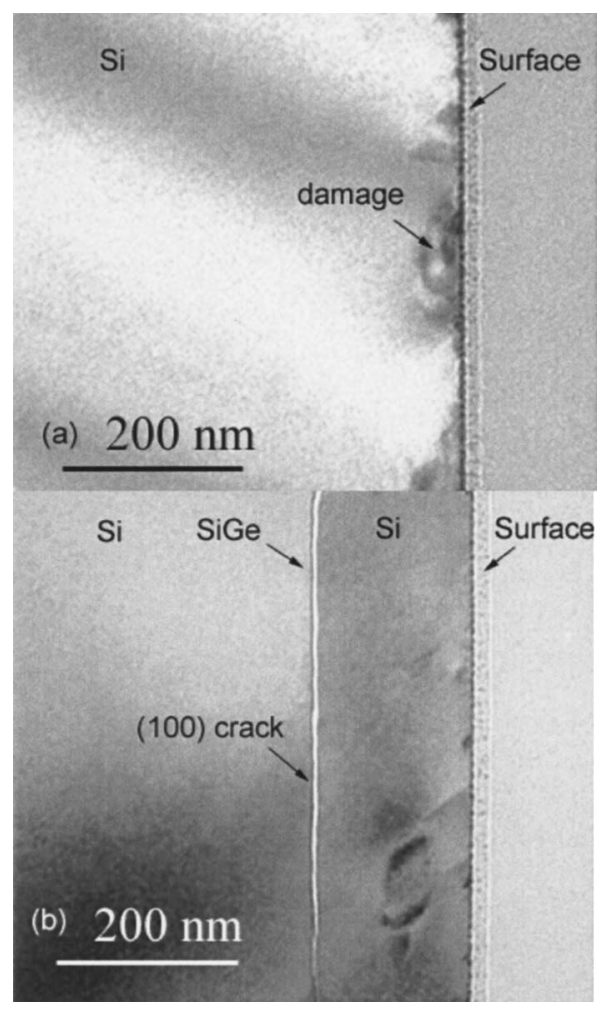

FIG. 4. TEM micrographs obtained from (a) the hydrogenated control Si sample (with a strained layer), and (b) the hydrogenated MBE sample (with a strained layer). 
sample. Figure 4(b) shows a continuous (100) crack, parallel to the $\mathrm{Si}$ surface in the hydrogenated MBE sample. It is evident from the TEM micrographs that our approach is capable of controlling the location of the crack by growing a thin strained layer at a desired depth.

It is worth noting that Fig. 2 shows that the splitting occurs for a $\mathrm{H}$ peak concentration of $\sim 2 \%$, which is much lower than the threshold $\mathrm{H}$ concentration $(\sim 5 \%)$ for splitting in conventional $\mathrm{H}$ ion implantation. ${ }^{5}$ The high efficiency of splitting in our approach might be explained by the high efficiency of $\mathrm{H}$ interaction with vacancy defects (mode $>2050 \mathrm{~cm}^{-1}$ ) and the absence of $\mathrm{H}$ interaction with interstitial defects $\left(\right.$ mode $\left.<2050 \mathrm{~cm}^{-1}\right){ }^{14}$ as evidenced by the IR data in Fig. 3.

The equilibrium vacancy concentration in $\mathrm{Si}$ at $650{ }^{\circ} \mathrm{C}$ is approximately $1 \times 10^{12} / \mathrm{cm}^{3} .{ }^{15}$ Including the effect of straininduced changes on vacancy formation energy, ${ }^{16,17}$ our estimated equilibrium vacancy concentration in the $\mathrm{SiGe}$ layer is less than $1 \times 10^{13} / \mathrm{cm}^{3}$. This value is too low to account for any substantial $\mathrm{H}$ trapping. However, gettering sites may also arise from hydrogenation-induced vacancies. Based on our previous studies on the nucleation and growth of platelets in hydrogen-ion-implanted $\mathrm{Si}^{18}{ }^{18}$ we believe that this strainfacilitated splitting results from two successive steps: (1) preferential vacancy aggregation in the compressively inplane strained layer and (2) facilitated $\mathrm{H}$ platelet formation due to the interaction of $\mathrm{H}$ with these vacancy aggregates. Previous studies have shown an outward relaxation of the lattice around a self-interstitial in $\mathrm{Si}$ and an inward relaxation of the lattice around a vacancy. ${ }^{19-21}$ Accumulation of interstitials within the compressively in-plane-strained SiGe layer is mediated primarily by vacancies diffusing towards the strained layer. ${ }^{20}$ Furthermore, clustering of vacancies is enhanced by the higher mobility of the vacancies along the compressive strain layer. ${ }^{22}$ High resolution electron microscopy of electron irradiated strained Si has shown preferential aggregation of vacancies on (001) planes within the SiGe layer. ${ }^{20}$ Various experiments have provided evidence that vacancies play a central role in $\mathrm{H}$ platelet formation. ${ }^{12,13,23,24}$ Chemical interaction of $\mathrm{H}$ with dangling bonds in vacancytype defects, and subsequent trapping of hydrogen lead to the formation of $\mathrm{H}$ platelets and ultimately to the formation of $\mathrm{H}_{2}$ gas bubbles. The building up of internal pressure with annealing will essentially lead to cracking. Recent firstprinciple calculation has proposed that hydrogen-vacancy clusters are the precursors for evolution into internal hydrogenated surfaces. ${ }^{24}$

From the viewpoint of throughput, MBE has limitations for growth on large size wafers. The required heterostructure can be fabricated by chemical vapor deposition, which has been widely used in high-flow processes.
In summary, we have demonstrated a new approach to transfer a thin Si layer by using a buried SiGe layer to provide $\mathrm{H}$ trapping centers during hydrogenation. This approach does not require any ion implantation steps. Blistering and subsequent layer separation can be controlled to occur within the SiGe layer. We explain this behavior as being due to preferential vacancy aggregation within the strained layer and subsequent trapping of hydrogen that lead to localized cracking in a well controlled manner.

This research is supported by the Department of Energy, Office of Basic Energy Science, and in part by the Office of Naval Research, and in part by City University of Hong Kong Strategic Research Grant (SRG) \#7001820. U.C.S.D. and A.S.U. gratefully acknowledge sponsorship from NSF.

${ }^{1}$ M. Bruel, Nucl. Instrum. Methods Phys. Res. B 108, 313 (1996).

${ }^{2}$ J. P. Collinge, Silicon-on-Insulator Technology: Materials to VLSI (Kluwer, Boston, 1991).

${ }^{3}$ G. K. Celler and Sorin Cristoloveanu, J. Appl. Phys. 93, 4955 (2003).

${ }^{4}$ International Technology Roadmap for Semiconductors, 2003 Edition, http://public.itrs.net

${ }^{5}$ O. Moutanabbir, A. Giguère, and B. Terreault, Appl. Phys. Lett. 84, 3286 (2004).

${ }^{6}$ C. Maleville, E. Neyret, E. Ecarnot, L. Arene, T. Barge, and A. J. Auberton, 2001 IEEE International Silicon-on-Insulator Conference, Piscataway, NJ, 2000, pp. 155-156.

${ }^{7}$ V. P. Popov, I. V. Antonova, V. F. Stas, L. V. Mironova, A. K. Gutakovskii, E. V. Spesivtsev, A. S. Mardegzhov, A. A. Franznusov, and G. N. Feofanov, Mater. Sci. Eng., B 73, 82 (2000).

${ }^{8}$ K. Henttinen, I. Suni, and S. S. Lau, Appl. Phys. Lett. 76, 2370 (2000).

${ }^{9}$ P. Chen, P. K. Chu, T. Höchbauer, M. Nastasi, D. Buca, S. Mantl, N. D. Theodore, T. L. Alford, J. W. Mayer, R. Loo, M. Caymax, M. Cai, and S. S. Lau, Appl. Phys. Lett. 85, 4944 (2004).

${ }^{10}$ P. Chen, P. K. Chu, T. Höchbauer, J.-K. Lee, M. Nastasi, D. Buca, S. Mantl, R. Loo, M. Caymax, T. Alford, J. W. Mayer, N. David Theodore, M. Cai, B. Schmidt, and S. S. Lau, Appl. Phys. Lett. 86, 31904 (2005).

${ }^{11}$ A. Usenko, J. Electron. Mater. 32, 872 (2003).

${ }^{12}$ M. K. Weldon, V. E. Marsico, Y. J. Chabal, A. Agarwal, D. J. Eaglesham, J. Sapjeta, W. L. Brown, D. C. Jacobson, Y. Caudano, S. B. Christman, and E. E. Chaban, J. Vac. Sci. Technol. B 15, 1065 (1997).

${ }^{13}$ B. B. Nielsen, L. Hoffmann, and M. Budde, Mater. Sci. Eng., B 36, 259 (1996).

${ }^{14}$ Y. J. Chabal, M. K. Weldon, Y. Caudano, B. B. Stefanov, and K. Raghavachari, Physica B 273, 274, 152 (1999).

${ }^{15}$ H. Bracht, N. A. Stolwijk, and H. Mehrer, Phys. Rev. B 52, 16542 (1995).

${ }^{16}$ N. E. B. Cowern, P. C. Zalm, P. van der Sluis, D. J. Gravesteijn, and W. B. de Boer, Phys. Rev. Lett. 72, 2585 (1994).

${ }^{17}$ P. Kringhøj, A. N. Larsen, and S. Y. Shirayev, Phys. Rev. Lett. 76, 3372 (1996).

${ }^{18}$ M. Nastasi, T. Höchbauer, J. K. Lee, A. Misra, J. P. Hirth, M. Ridgway, and T. Lafford, Appl. Phys. Lett. 86, 154102 (2005).

${ }^{19}$ A. Antonelli and J. Bernholc, Phys. Rev. B 40, 10643 (1989).

${ }^{20}$ L. Fedina, O. I. Lebedev, G. Van Tendeloo, J. Van Landuyt, O. A. Mironov, and E. H. C. Parker, Phys. Rev. B 61, 10336 (2000).

${ }^{21}$ S. Ogut, H. Kim, and J. R. Chelikowsky, Phys. Rev. B 56, R11353 (1997).

${ }^{22}$ M. J. Aziz, Appl. Phys. Lett. 70, 2810 (1997).

${ }^{23}$ T. Höchbauer, A. Misra, M. Nastasi, and J. W. Mayer, J. Appl. Phys. 89, 5980 (2001).

${ }^{24}$ F. A. Reboredo, M. Ferconi, and S. T. Pantelides, Phys. Rev. Lett. 82, 4870 (1999). 